\title{
Reciprocals in Kipsigis
}

\author{
Bii John Kibet. \\ Department of Linguistics and Foreign Languages, Moi University, Kenya
}

\begin{abstract}
In this paper, I investigate the reciprocal constructions in Kipsigis language.The language mainly marks reciprocity on the verb by a morpheme -kee-, though some verbs will also take-yo-morpheme.It is established that a reciprocal morpheme can be used to mark several situations such as coding, chaining, collective and distributive where they all semantically share a property of plurality of relations among arguments while at the same time having an effect on the argument structure. The reciprocal marked constructions in Kipsigis all require a plural NP as their external arguments.Transitivity of the verb is also affected by the suffixation of the reciprocal morpheme -kee-. Studies concerning reciprocals have observed that reciprocal constructions derive intransitive structures, a closer look at the Kipsigis reciprocal reveals that apart from deriving an intransitive construction, the number of arguments is reduced in both transitive and ditransitive construction, i.e. it changes a transitive verb into an intransitive one, and a ditransitive verb into transitive.
\end{abstract}

Keywords:Reciprocals, Coding, Chaining, Collective, Distributive, Transitivity, Argument.

\section{Introduction}

Reciprocals are expressed differently in different languages. Some languages mark reciprocity by means of a reciprocal nominal while others through verbal morphology. In English reciprocals are marked by lexical items; each other or one another, as in (1) where they express anaphoric relations between items in the constructions. On the other hand, Kiswahilishows reciprocity on the verbs by a bound morpheme -an-as shown in example (2);

$$
\begin{aligned}
& \text { 1. The children kicked one another. } \\
& \begin{array}{l}
\text { Tu- na- pend- an-a } \\
\text { SAls-Pres -like- Rec-IND } \\
\text { We like each other. }
\end{array} \text { (Kamil, 2003)[1] }
\end{aligned}
$$

Kipsigis (Nilotic, Kenya) expresses most of the derivational morphemes as suffixes as opposed to prefixes. A reciprocal relation in the language is mostly expressed by a verbal affix -kee, thoughthere is also a group of verbs that mark reciprocity by a bound morpheme -yo-.These markers are productively conjugated to the verb as suffixes where they have an effect on the morphological structure of the verb as well the argument structure, (Bii, 2009)[2]. This paper aims at giving a descriptive account of the verbal reciprocal marker in the language with a purpose of contributing to the knowledge of verbal extensions.

2.1 Reciprocal Marker -kee

\section{Verbal Reciprocal Markers}

Reciprocal in Kipsigis is mainly marked on the verbs by a bound morpheme-kee, as illustrated below:

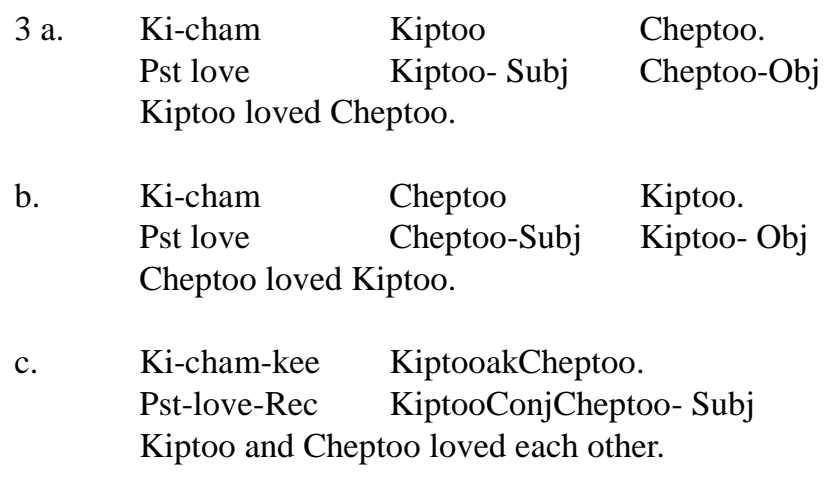


In order to encode a situation in ( $3 a$. and b.), the two simple situations are combined with a reciprocal kee. This means that a structure expressing reciprocity in Kipsigis needs to have a verbal suffix -kee. When we compare structures in (3a-b)withsentence (c), we note that -kee is affixed to the root of the verb. The situation in (3c) therefore implies that the clause describes a reciprocal situation and not just the situation denoted by the verb -cham 'love' without repeating the verb for each simple situation. The affixation of reciprocal -kee as observed also brings forth the incorporation of a conjunction to realize a plural NP which is the subject. Furthermore, the syntactic feature evident between the reciprocal sentence and its' non-reciprocal structure, is that the number of arguments decreases once the reciprocal marker is suffixed to the verb. In examples (3a.\& b.), the verb takes two arguments-i.e. an external argument Kiptoo and an internal argument Cheptoo. In the reciprocal structure, the sameverb which is marked by -kee takesa single-plural denoting NP argument. This means a reciprocal in the language reduces the valence of the verb by demoting the object. Transitivity will be looked at in detail in Section 5.

\subsection{Reciprocal Marker -yo-}

English language contains lexical verbs like 'exchange' and 'meet' that do not require a reciprocal anaphor to express a reciprocal situation as illustrated in example (4);

$$
\begin{aligned}
& \text { 4. Peter and Mary exchanged flowers } \\
& \text { Peter conj Mary -Subj V flowers-Obj }
\end{aligned}
$$

In (4), 'exchange' takes a plural external argument. The situation described is the one where each member of the plural argument performs the same action. The commonly used reciprocal marker 'each other' or 'one another' is absent in the construction yet reciprocity is still expressed. These types of verb are therefore said to inherently possess a reciprocal situation.

An examination of such verbs in Kipsigis shows that -yo- affix and not -kee morpheme has to be

\begin{tabular}{|c|c|c|c|}
\hline 5. a. & $\begin{array}{l}\text { Ki- nyor } \\
\text { Pst-meet }\end{array}$ & $\begin{array}{l}\text { Lang' at } \\
\text { Lang'at-Subj }\end{array}$ & $\begin{array}{l}\text { Kirui. } \\
\text { Kirui-Obj }\end{array}$ \\
\hline & Lang'at met Kir & & \\
\hline b. & Ki-tui-yo & Lang'atakKirui & \\
\hline & Pst-meet-Rec & Lang'at Conj. & Kirui-Subj \\
\hline & Lang'at and Kir & i met each other. & \\
\hline 6. a. & Ki-bol-chi & Kibet & Koech \\
\hline & Pst-quarrel-App & Kibet-Subj & Koech-Obj \\
\hline & Kibet quarreled & tt Koech & \\
\hline 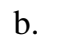 & Ki-bol-yo & Kibet ak & Koech \\
\hline & Pst-quarrel-yo & Kibet Conj & Koech-Subj \\
\hline
\end{tabular}
involved for reciprocity to be expressed. Note the following examples:

The examples in (5 b) and (6 b), shows the arguments expressing a bi-directional act while in (5 a) and (6 a)denote a uni-directional act. In (5a), the external argument, Langat is the onemeeting the internal argument Kirui. In (5b), the situation described is the onewhere both arguments; Langat and Kirui meet each other. Example, (6a) showsKibet quarreling internal argument Koech. However, in (6b), the members of the same group, 'Kibet' and 'Koech' quarrel one another. Such verbs (nyor 'meet' and bol'quarrel') in the language rely on the reciprocal marker -yo- to express a reciprocal situation.

\section{Functions of -kee}

It is usual for a reciprocal marker to serve more than one function cross-linguistically. Lichtenberk $(1985,2000)$ [3] [4] in his exposition of some oceanic languages observes that reciprocals have been noted to encode different situations, such as; distributive, collective, chaining, repetitive among others. The situations encoded by the same constructions are then said to share similarities which may involve:

a) The plurality of relations among the participants, and

b) The low elaborations or elaborations of situations which subsumes low distinguishability of participants and sub-events. 
Low distinguishability of participants in such a case imply the similarity of functions played by the participants engaged in an event while low distinguishability of sub-events refers to underspecifity of the temporal configuration of the sub-events. For instance, in a reciprocal situation, a participant A stands in a certain relation to participant in $\mathrm{B}$, and $\mathrm{B}$ stands in the identical relation to A. In a distributive event, the participants perform asimilaractivity but at a different time and / or place.

Davis (2000) [5] while studyingMadurese reciprocals, establish that the reciprocal and distributive situations coded by a marker 'Saleng' all involve multiple events. In Kipsigis, the Verbal suffix -kee is mainly used to mark reciprocity. Though, the morpheme can also encode chaining, distributive and collective situations. Syntactically, the application of this affix requires the subject to be in plural form. Semantically, the arguments entailthe notion of plurality with regard to the number of participants or sub-events involved in the activity.

\subsection{Reciprocal situation}

The main function of a reciprocal morpheme -kee in Kipsigis as indicated in the previous section is to indicate reciprocity of the action denoted by the verb. As in figure (1a). The variation in reciprocity occurs in instances where there are more than two participants involved in an activity denoted by the verb. The situations can be illustrated in figures (1b-d).

(a)

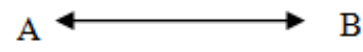

(b)

(c)
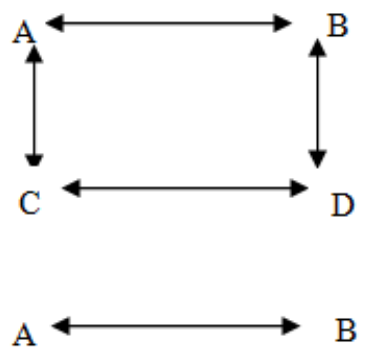

(d)
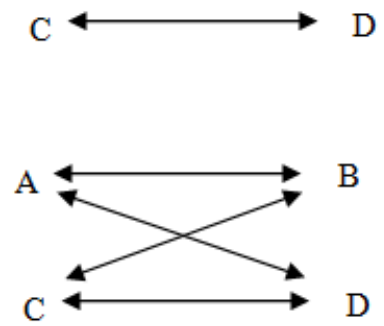

figure1.

In order to put the above situations into focus, let us consider the following structures;
Ki-chup-kee
Kibet
akChebet
Pst-insult-Rec
Kibet ConjChebet-Subj
Kibet and Chebet insulted each other.

Ki-pir- kee Lagok
Pst-fight-Rec Children- Subj
The children fought (each other).

In example (7), there are only two participants in the subject position, Kibet and Chebet. They thus share a relation shown in fig. (1a). Such a relation, shows two simple situations, 'Kibet loved Chebet', and 'Chebet loved Kibet'. In example (8), the situations involve more than two participants implying the existence of different variations of the relations. The relation may be that of fig. (1b), (1c) or (1d). 


\subsection{Collective Situations}

In a collective situation, the participants denote a group rather than individuals, and perform an activity expressed by the verb jointly. Such a situation is still marked in the languageby a suffix -keeas in the following sentences:

$$
\begin{aligned}
& \text { Ki-ki-tem-chi- kee mbaret } \\
& \text { Pst-1Pl/Subj-plough-Appl-Rec land-Obj } \\
& \text { We ploughed the land for one another. }
\end{aligned}
$$

$$
\begin{aligned}
& \text { *Ki-ki- tem-kee mbaret. } \\
& \text { Pst-1Pl/Subj-plough-Rec land-Obj } \\
& \text { We ploughed land one another. }
\end{aligned}
$$

Tun-toret-i-kee SandetakMoning'otiot.

Fut-assist-Asp-Rec Husband Conj Wife-Subj

The husband and the wife will be assisting one another.

In structures (9-11), the subjects are regarded as a whole performing an activity together. In (9), the likely situation is that the land was not ploughed by an individual for himself or herself but "we" ploughed itfor one another. The applicative morpheme -chi- introduces a benefactive role where each one of the arguments benefited. The absence of an applicative affix in construction having pronominal plural subject makes the sentence ungrammatical in example 10. Therefore, an applicative marker is obligatory in a sentence construction containing a reciprocal marker when it expresses a collective situation. Example (11) shows a scenariowhere the subjects;SandetakMoning'otiot 'husband and wife', will be assisting one another. In some instances, morpheme -kee- which marks a reciprocal can be used to mark collectivity.

Consider:

$$
\begin{aligned}
& \text { Tun-o- rir-chi- kee } \\
& \text { Pst-2nd pl/Subj-cry-Appl-Rec } \\
& \text { You will cry for each other. }
\end{aligned}
$$

In (12), the plural denotingexternal argument-o-might be havingthe same sad experience and therefore all of them engage in the act of crying. In such a case, -kee is marked on a one-predicate argument rir 'cry' to signala collective activity.

\subsection{Chaining Situation}

In other structures, there are reciprocal situations where the relation of the participants is expressed as a chain. Lichtenberk (op cit) term this an open chain; see fig.(2) and closed chain in fig. (3).

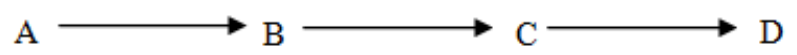

figure 2: An open chain situation

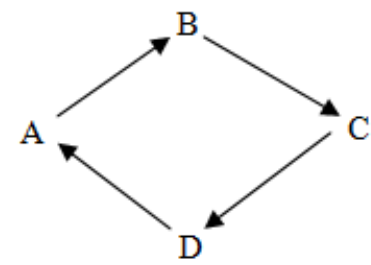

figure 3: A closed chain situation

In fig. 2, except for the initial and end participant, that is $\mathrm{A}$ and $\mathrm{D}$, all the other partakers (B and $\mathrm{C}$ ) are involved in two relations. For example, participant $\mathrm{B}$ follows participant $\mathrm{C}$ and at the same time is followed by participant A. In a closed chain, there is no end participant; all the participants are involved in two relations,just like participants B and C in fig. 2.

In Kipsigis, chaining situations both in an open and closed can also be relayed by a reciprocal 
morpheme-kee-whichsuffixed to the verb; Consider:

\begin{tabular}{|c|c|c|}
\hline \multirow[t]{2}{*}{ 13.a } & $\begin{array}{l}\text { Ki-sup-kee } \\
\text { Pst-follow-Rec }\end{array}$ & $\begin{array}{l}\text { Kipsomaninik } \\
\text { Students-Subj }\end{array}$ \\
\hline & \multicolumn{2}{|c|}{ The students followed each other. } \\
\hline b. & Ki-won-kee & Kipsomaninik \\
\hline & Pst-chase-Rec & Students-Subj \\
\hline
\end{tabular}

In sentence $13 \mathrm{a}$, the situation presented is that of an open one. The participants' kipsomaninik 'students' are involved in either one relation or two relations. In an open situation, the first student and the last are involved in one relation while the other participants engage in two relations towards each other.

In $13 \mathrm{~b}$, the students are in a multiple reciprocal relation in which each two of the participants' form a pair and each of them perform a reciprocal act of following, as shownby fig. (1c). Similarly, the subject kipsomaninik'students' may form a closed chain where one participant, a student, chased another participant, another student, and at the same point the activity of chasing is expressed by the third participant, another student and so on depending on the number of participants involved.

\section{Kee-marked construction licensing.}

The reciprocal morpheme -kee serves several functions in the language. As outlined previously, the reciprocal markers can mark several situations. These situations imply the involvementof plurality of relations with the participants involved. Reciprocity is made clear by the requirement of reciprocal constructions to possess a plural denoting subject. After the suffixation of $-\mathrm{kee}$, the derived reciprocal verbs require plural subjects.

$\begin{array}{lll}\text { 14.a. } & \begin{array}{l}\text { rip-e-kee } \\ \text { take care-Pres-Rec } \\ \text { The wife and the husband }\end{array} & \begin{array}{l}\text { Moning'otiot-ak-Sandet } \\ \text { Wife-Conj-Husband-Subj }\end{array} \\ \text { b. } & \begin{array}{l}\text { rip-e-kee } \\ \text { take care-Pres-Rec of each other. }\end{array} & \begin{array}{l}\text { Moning'otiot } \\ \text { Wife-Subj }\end{array}\end{array}$

The wife takes care of herself.

In example (14.b), the absence of plural-subject changes the semantic aspect of the construction. In Kipsigis, the reciprocal and reflexive markers are formally identical. Kemmer (1997)[6] notes that the semantics of a potentially ambiguous clause as a whole is bound to play an important role in its interpretation of structures as either reflexives or reciprocals.

The inherent reciprocal verbs also requires plural Noun phrase (see example 15a and b). This indicates that the requirement is related to the semantic content of the verbs in a sentences involved. Verbs such as wal'exchange' in Kipsigis denote reciprocal meaning by themselves although the suffixation of the reciprocal morpheme is also possible. Despite the absence or presence of the morpheme, the reciprocal content in them still requires plural subjects for the structures to be grammatical.

\begin{tabular}{ll} 
15.a. & Ki-ki-wal \\
Pst-1pl/Subj-exchange & \multicolumn{1}{c}{$\begin{array}{l}\text { Ngoroik } \\
\text { Clothes-Obj }\end{array}$} \\
We exchanged clothes. & \\
b. & Ki-ki-wal-chi- kee \\
Pst-1pl/Subj-exchange-Appl-Rec Clothes-Obj \\
We exchanged clothes for one another.
\end{tabular}

In addition to reciprocal constructions, other structures marked by the marker kee- including chaining or collective, are also bound by a need to have a plural subject. 


\section{Arguments in Reciprocal constructions}

This section discusses the arguments involved in reciprocal constructions in Kipsigis. Studies of reciprocal structures in other languages like English often lead to the conclusion that a reciprocal is an intransitivizer. Other Kipsigis structures suggests otherwise. Kipsigis data shows the reciprocal affix functioning asan argument-changing morphemeand not necessary an intransitivizer. This can be looked at in terms of the verbs classes involved.

\subsection{Intransitive Roots}

Payne (1997) [7] argues that intransitive verbs are grammatical when one argument is selected by the verb. It can be identified because they do not take two full NPs. Consider:

A person will die........

$\begin{array}{lll}\text { 18.a } & \begin{array}{l}\text { Ki-rir } \\ \text { Pst-weep } \\ \text { Jesus wept. }\end{array} & \text { Jeisu } \\ \text { b. } & \begin{array}{l}\text { *Ki-rir-kee } \\ \text { Pst-weep-Rec } \\ \text { Jesus wept........ }\end{array} & \text { Jeisu } \\ & \text { Jeisu-Subj } \\ \text { 19.a. } & \text { Tun-me Chiito } & \\ & \text { Fut-die } & \text { Person-Subj } \\ & \text { A person will die. } \\ \text { b. } & \text { *Tun-me-kee } \quad \text { Chiito } \\ & \text { Fut-die-Rec } & \text { Person-Subj }\end{array}$

As mentioned earlier, with regard to the syntax of the reciprocals, the reciprocal constructions derive intransitive structures. Looking at the intransitive constructions (18-19), after the suffixation of -kee, the resultant construction is ungrammatical. The plural-subject requirement cannot be satisfied; therefore reciprocity of the action is not met. Grammaticality of the intransitive verbs is only met achieved when the subject denotes plurality of participants.

\subsection{Transitive roots}

Transitive verbs ideallytake two arguments.In Kipsigis, the reciprocal marker -kee derive an intransitive verb by suppressing one of the arguments of the transitive verbal constructions.

\begin{tabular}{llll} 
20.a & $\begin{array}{l}\text { Ki-tun } \\
\text { Pst-marry }\end{array}$ & \multicolumn{1}{c}{$\begin{array}{l}\text { Kibet } \\
\text { Kibet-Subj married Chep. }\end{array}$} & $\begin{array}{l}\text { Chep } \\
\text { Chep-Obj }\end{array}$ \\
b. & $\begin{array}{l}\text { Ki-tun } \\
\text { Pst-marry }\end{array}$ & $\begin{array}{l}\text { Chep } \\
\text { Chep-Subj }\end{array}$ & $\begin{array}{l}\text { Kibet } \\
\text { Kibet-Obj }\end{array}$ \\
& Chep married Kibet. & \\
c. & Ki-tun-kee & Kibet ak & Chep \\
& Pst-marry-Rec & Kibet Conj & Chep-Subj
\end{tabular}

Kibet and Chepmarriedone another.

The verb tun 'marry' is originally a two place predicate having, a subject and an object. Therefore, in order to encode the situations in (20a-b), there is a combination of the two structures. The suffixation of a reciprocal marker -kee, as in (20c), deriveski-tun-kee 'marryone another' which takes only one argument- the subject, indicating thatthe reciprocal marker-kee has reduced the number of arguments from two to one. The expression in $(20 \mathrm{c})$ implies that the clause describes a reciprocal situation denoted by the verb tun 'marry' without repeating the verb for each situation.

\subsection{Ditransitive Verbs}

A ditransitive verb normally takes three arguments; a subject, a direct object and an indirect object. Consider the following examples: 
21 a. Ki-gochiKeter

Pst-give Keter-Subj

Keter gave Chelel a letter.
Chelel baruet

Chelel-Obj ${ }^{\mathrm{i}}$

letter-Obj $^{\mathrm{d}}$

b. Ki-gochi-kee

Keter and Chelel gave each other a letter.

\author{
Keter-ak-Chelel baruet
}

In (21a), kigochi 'gave' takes three arguments without a reciprocal morpheme, these are; agent who gave the letter, patient 'the letter', and beneficiary 'Chelel'. In the reciprocal construction, the number of arguments is reduced from three to two. In (21.b), the remaining two arguments are KeterakChelel 'Keter and Chelel' and baruet 'letter'. Since the predicate involved in reciprocal constructions expresses a symmetric relation, what is represented by two arguments in a non-reciprocal construction is not represented by a single argument in a reciprocal construction. In other words, the number of arguments is reduced. The reciprocal in Kipsigis is thus regarded as a valence reducing morpheme.

Therefore, as noted, the morpheme -kee does necessarily derive intransitive verbs; rather, it reduces the number of arguments of the suffixed verbs, i.e it changes transitive verbs into intransitive ones and ditransitive verbs into transitive.

\section{Conclusion}

From the discussion, it is established that a reciprocal in Kipsigis is mainly marked on the verbs by a suffix -kee. Morpheme -yo- can also be used with certain of verbs to express reciprocity. In addition to marking reciprocals, -kee is also used to mark chaining, distributive and collective situations, which all share a semantic property of plurality of relations. It is also noted that a reciprocal is a valence-reducing morpheme in the language and not necessarily an intransitivizer.

\section{References}

[1]. Kamil, U.D., The Acquisition of Nairobi Swahili: The Morphosyntax of Inflectional Prefixes and Subjects, Doctoral Dissertation, University of California, U.S.A, 2003.

[2]. Bii, K. J., TheMorphosyntax of the Kipsigis Verb Phrase. Unpublished M. Phil Thesis, Moi University, Eldoret,2009.

[3]. Lichtenberk, F., Multiple Uses of Reciprocal Constructions. Australian Journal of Linguistics, 5, 1985, 19-41.

[4]. Lichtenberk, F., Reciprocal without Reflexives, Reciprocals: Forms and Functions. In Frajzyngier Z. and Traci, S. (Eds), Typological Studies in Language, no 4. (Amsterdam; Philadephia: John Benjamins, 2000), 31-62.

[5]. Davies, W.D., Events in Madurese Reciprocals. Oceanic Linguistics, 39, (1), 2000, 123-143.

[6]. Kemmer, S., Reciprocals and their Semantic Affinitives: where Unity meets Multiplicity. Paper presented at the symposium on Reflexives and Reciprocals.University of Colorado. Boulder, 1997.

[7]. Payne, T.E, Describing Morphosyntax: A Guide to Field Linguistics. Cambridge: CambridgeUniversity Press, 1997 